\title{
Proximal aortic stiffness in the paediatric adolescent population
}

\author{
Adam J Nelson ${ }^{1 *}$, James D Cameron ${ }^{2}$, Adelene C Kaihui ${ }^{1}$, Angelo Carbone', Scott R Willoughby', \\ Cameron J van den Heuvel', James A Martin', Declan Kennedy ${ }^{1}$, Stephen G Worthley ${ }^{1}$, Matthew I Worthley ${ }^{1}$ \\ From 2011 SCMR/Euro CMR Joint Scientific Sessions \\ Nice, France. 3-6 February 2011
}

\section{Objective}

The aim of this study was to assess whether arterial stiffness increases in the second decade of life.

\section{Background}

Pathological studies have shown that atherosclerotic disease begins in early childhood. Furthermore, associations between risk factors and early atherosclerotic disease are evident in this population and therefore may be linked to future symptomatic coronary events.

While we have shown that ageing preferentially stiffens the proximal aorta in an adult population, it is uncertain whether this also occurs in an adolescent cohort.

\section{Methods}

The evaluation of arterial stiffness was performed by gated magnetic resonance imaging (MRI, 1.5T Siemens Sonata) TrueFISP (fast imaging with steady state free precession) cine sequence with off-line analysis (ImagePro Plus, MediaCyberkinetics, USA). Cross-sectional measurements of aortic areas $\left(\mathrm{mm}^{2}\right)$ were undertaken at 3 locations: the ascending (AA), proximal descending (PDA) and distal descending aorta (DDA). Arterial stiffness was evaluated by aortic distensibility [(maximal aortic area - minimal aortic area)/(brachial pulse pressure $\mathrm{X}$ minimal aortic area)].

\section{Results}

Ten paediatric ( $10.6 \pm 2.3$ years) and ten young adults $(20.3 \pm 0.5$ years) underwent cardiovascular magnetic resonance assessment of arterial stiffness.
Table 1

\begin{tabular}{lllll}
\hline & & Pediatrics & Young Adult & $\mathbf{p}$ \\
\hline Brachial Pulse Pressure $(\mathrm{mmHg})$ & $38.3 \pm 7.4$ & $44.7 \pm 9.1$ & NS \\
\hline Aortic Distensibility $\left(\mathrm{mmHg}^{-1}\right)$ & AA & $12.5 \pm 4.6$ & $7.8 \pm 2.7$ & 0.013 \\
\cline { 2 - 5 } & PDA & $9.6 \pm 4.7$ & $7.6 \pm 2.5$ & NS \\
\cline { 2 - 5 } & DDA & $12.9 \pm 7.7$ & $9.9 \pm 3$ & NS \\
\hline
\end{tabular}

A significant difference (one-way ANOVA) is apparent in AA distensibility between the paediatric and young adult cohort $(p<0.05)$ with no significant difference at the two more distal planes of assessment.

\section{Conclusions}

This is the first study to demonstrate a similar pattern of heterogenous stiffening occurring as early as the 2nd decade. These results must be interpreted in the context of this study being cross sectional in nature and involving only a small number of subjects. Nonetheless these findings warrant further assessment through a prospective, longitudinal study to further evaluate this parameter as a potential unique early marker of future cardiovascular events.

\section{Author details}

'University of Adelaide, Adelaide, Australia. ${ }^{2}$ Monash Cardiovascular Research Centre, Melbourne, Australia.

Published: 2 February 2011

doi:10.1186/1532-429X-13-S1-P389

Cite this article as: Nelson et al:: Proximal aortic stiffness in the paediatric adolescent population. Journal of Cardiovascular Magnetic Resonance 2011 13(Suppl 1):P389.

'University of Adelaide, Adelaide, Australia

Full list of author information is available at the end of the article

(c) 2011 Nelson et al; licensee BioMed Central Ltd. This is an open access article distributed under the terms of the Creative Commons 